\title{
Isatin as a simple, highly selective and sensitive colorimetric sensor for fluoride anion
}

https://doi.org/10.1515/hc-2020-0003

Received October 12, 2019; accepted January 24, 2020.

Abstract: Herein, we report the fluoride anion sensing properties of a commercially available and inexpensive organic compound, isatin, which is found to be a highly selective and sensitive sensor. In naked-eye experiments, by addition of fluoride anions, isatin shows a dramatic color change from pale yellow to violet at room temperature, while the addition of other anions, i.e. $\mathrm{Cl}^{-}$, $\mathrm{Br}^{-}, \mathrm{I}^{-}, \mathrm{ClO}_{4}^{-}, \mathrm{H}_{2} \mathrm{PO}_{4}^{-}$and $\mathrm{PF}_{6}^{-}$, did not induce any colour change. Additionally, recognition and titration studies have also been done through UV/Vis spectroscopy. Isatin displayed a new absorption band at $533 \mathrm{~nm}$ after the addition of fluoride anions, which is presumably due to acid-base interaction between isatin and fluoride anions, while other anions did not trigger noticeable spectral changes. The detection limit was observed to be $0.367 \mathrm{ppm}$. DFT calculations were also performed to further explain the behavior of receptor 1 towards the $\mathrm{F}^{-}$anion. Owing to high sensitivity and selectivity, isatin can be useful in the detection of biologically or environmentally important fluoride anions at very low concentration.

Keywords: Isatin, chromogenic sensor, ion detection; fluoride, UV-Vis titrations, DFT calculations

\section{Introduction}

In our everyday life, anions are valuable because they regulate and/or are responsible for numerous environmental and biological processes [1-16]. For instance, anions are involved in the production of electrical signals, controlling osmotic pressure, activating signal

\footnotetext{
* Corresponding author: Muhammad Moazzam Naseer, Department of Chemistry, Quaid-i-Azam University-45320, Islamabad, Pakistan, E-Mail: moazzam@qau.edu.pk, Tel+92-519064-2129.

Azeem Haider, Mukhtiar Ahmed and Muhammad Faisal, Department of Chemistry, Quaid-i-Azam University-45320, Islamabad, Pakistan.
}

transduction pathways, maintaining cell volume, etc [17]. Therefore, the changes in anion flux across cell membranes is increasingly being identified as the foremost cause of various disorders including osteoporosis [18], Pendred's syndrome [19], Dent's disease [20], Bartter's syndrome [21] and cystic fibrosis [22]. Further, anions are important for many industrial processes and are often found as harmful pollutants [23]. Also, anions are present in almost $70 \%$ of all active sites of enzyme, which play a significant part in genetic information storage [24]. Moreover, anions play crucial roles in the fields of catalysis and medicine, although pollutant anions have been mainly linked to carcinogenesis (metabolites of benzoate and acetate) [25], eutrophication of rivers (from the application of phosphate-based fertilizers) [26] and contamination of drinking water (by fluoride pollution) [27].

Among anions, fluoride is the most important, owing to its involvement in numerous environmental and biological processes [28-31]. Fluoride is known to have a hard Lewis base nature, the smallest ionic radius, and the highest charge density of any anion [32]. Naturally, fluoride ions occur in the sea, in soils and rocks, and in groundwater supplies. Numerous studies have shown that fluoride in drinking water or toothpaste can help with dental health $[33,34]$. Also, fluoride can help increase bone mass and hence has the potential for treating osteoporosis $[35,36]$. Because of these benefits, water fluoridation had become widely used by 1960 [37]. However, later studies have shown that overexposure to fluoride can be detrimental, especially to the teeth [38], brain [39], kidney [40] and bone [41], resulting in a disease known as fluorosis. This diversity of function of the fluoride anion, both the benefits and perniciousness, makes its detection of considerable interest. In this context, organic colorimetric chemosensors are of particular importance due to their simplicity [29, 42-46]. Color changes visible to the naked eye are preliminarily used as signals for detection of anions without any equipment being required. However, the synthesis of such chemosensors usually requires expensive reagents, and long or tedious synthetic processes, making them less applicable. Therefore, the development of a cheap, non-corrosive, environment friendly, safe, selective, and sensitive chemosensor remains attractive [42, 43]. 
Isatin ( $1 \mathrm{H}$-indole-2,3-dione) 1 (Figure 1$)$ is a commercially available and inexpensive organic compound that was first discovered by Erdman and Laurent in 1840 as an oxidation product of indigo [47]. Almost 140 years after its discovery, it was identified as a natural product present in plants, animals, fungi, symbiotic bacteria and marine molluscs [47]. Isatin 1 is also considered important in many physiological pathways [48-50]. Apart from its applications in medicinal chemistry [47], it has been extensively employed as a signaling unit in various receptors [51, 52] and some of its derivatives have also been investigated as chemosensors for anion detection $[53,54]$. Careful analysis of its features reveals that isatin 1 has an acidic $\mathrm{NH}$ group and intense color which are prime requirements for a chemosensor [29, 42-46]. The interesting structure combined with our recent interest in isatin-derived compounds [55-59] and in developing chemosensors $[6,60]$ motivated us to investigate the behavior of commercially available isatin as an anion sensor. Fascinatingly, as discussed below, isatin is found to be a highly selective and sensitive chemosensor for fluoride anions in the presence of various other anions, as its acidity allows it to interact only with fluoride anions. To the best of our knowledge, this is one of the cheapest chemosensors reported so far for the selective recognition/ sensing of the fluoride anion.<smiles>O=C1Nc2ccccc2C1=O</smiles>

Isatin

(Indoline-2,3-dione)

Figure 1 Structure of isatin.

\section{Results and discussion}

As isatin 1 is a colored compound,its potential in anion recognition/sensing was first monitored by naked eye experiments. This method of sensing is highly valued due to its low cost and easy detection without the help of any instrument or equipment [29, 42-46]. Interestingly, the addition of one equivalent of $\mathrm{F}^{-}$anion to the solution of isatin 1 resulted in a dramatic color change from pale yellow to violet, clearly visible to the naked eye. Most importantly, the color change was observed even at a low concentration of fluoride anion (10mM). In contrast, the addition of other anions resulted in no visible changes in color (Figure 2).

After obtaining the preliminary information of selectivity for fluoride anion with naked eye experiments (Figure 2), the chemosensor 1 was further evaluated by UV-Vis spectroscopy. Absorption spectra were recorded after the addition of one equivalent of different anions to the solution $(0.01 \mu \mathrm{M})$ of isatin $1 \mathrm{in} \mathrm{MeCN}$ to observe the selectivity pattern. All the solutions were well shaken to ensure the homogeneity of the solutions before recording the absorption spectrum. Figure 3 shows the changes in the UV-Vis spectra of 1 upon the addition of $\mathrm{F}^{-}, \mathrm{Cl}^{-}, \mathrm{Br}^{-}$, $\mathrm{I}^{-}, \mathrm{ClO}_{4}^{-}, \mathrm{H}_{2} \mathrm{PO}_{4}^{-}$and $\mathrm{PF}_{6}^{-}$(as their tetra- $n$-butylammonium salts). As shown in the Figure 2, 1, which absorbs at 410 $\mathrm{nm}$ in MeCN solvent, demonstrated a new and bathochromic shifted absorption band at $533 \mathrm{~nm}$ after the addition of fluoride anion. A bathochromic shift of more than 100 $\mathrm{nm}$ may be attributed to the hydrogen bonding/acid-base interaction between 1 and the fluoride anion. In other words, the interaction of fluoride anion with 1 caused hydrogen-bond or negative charge (in case of complete deprotonation)-induced electron delocalization. Under similar conditions, no changes in the absorption spectra could be observed upon addition of other anions, i.e. $\mathrm{Cl}^{-}$,

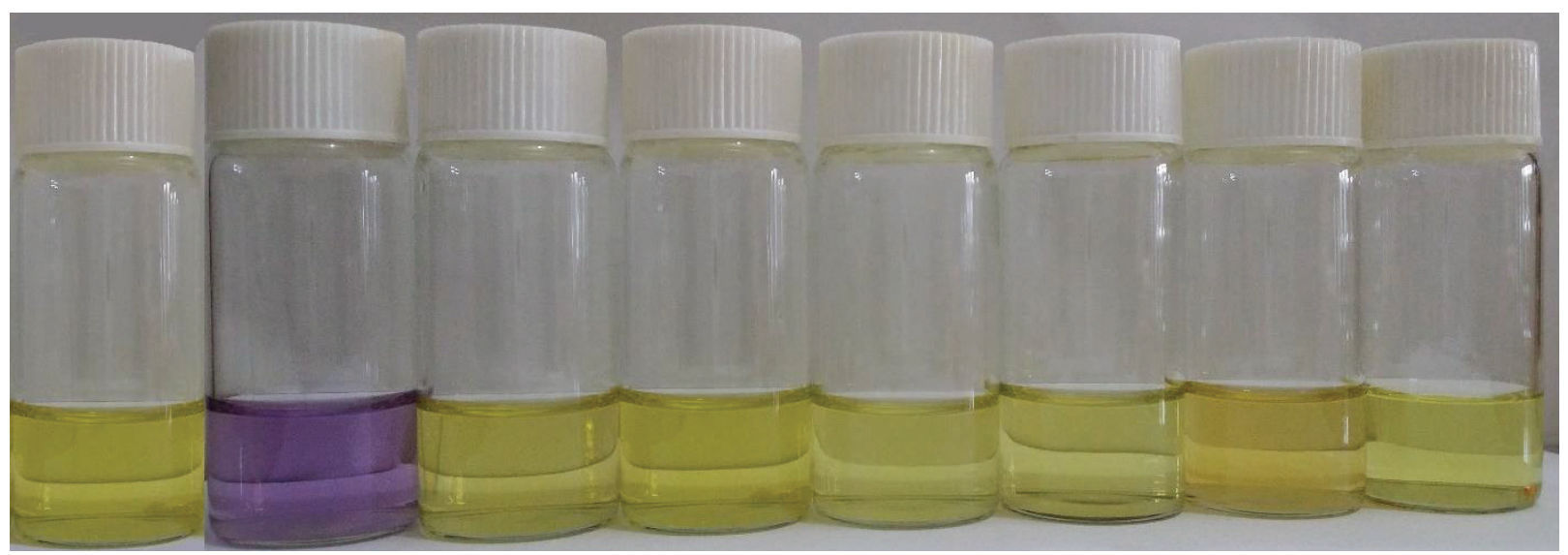

Figure 2 Color changes of the chemosensor $1(0.01 \mu \mathrm{M})$ in $\mathrm{MeCN}$ with the addition of 1 equivalent tetrabutylammonium salts (from left to right: $1, \mathrm{~F}^{-}, \mathrm{Cl}^{-}, \mathrm{Br}^{-}, \mathrm{I}^{-}, \mathrm{ClO}_{4}^{-}, \mathrm{H}_{2} \mathrm{PO}_{4}^{-}$and $\mathrm{PF}_{6}^{-}$). 
$\mathrm{Br}^{-}, \mathrm{I}^{-}, \mathrm{ClO}_{4}^{-}, \mathrm{H}_{2} \mathrm{PO}_{4}^{-}$and $\mathrm{PF}_{6}^{-}$. These results clearly indicate the ability of 1 for selective fluoride ion recognition in the presence of various other anions (Figure 3).

After ascertaining that compound 1 can recognize fluoride anions preferentially over other anions, titration studies were performed to check the quantitative behavior of this chemosensor towards different concentration of fluoride anion (Figure 4). In these studies absorption spectra were recorded for each concentration of fluoride anion. It was observed that by gradually increasing the concentration of fluoride anion, the intensity of the absorption band of 1 at $410 \mathrm{~nm}$ decreased and the intensity of the absorption band at $533 \mathrm{~nm}$ increased with a sharp isobestic point development at $470 \mathrm{~nm}$, indicating the existence of only two species in equilibrium throughout the titration process (Figure 5). From this, it may be

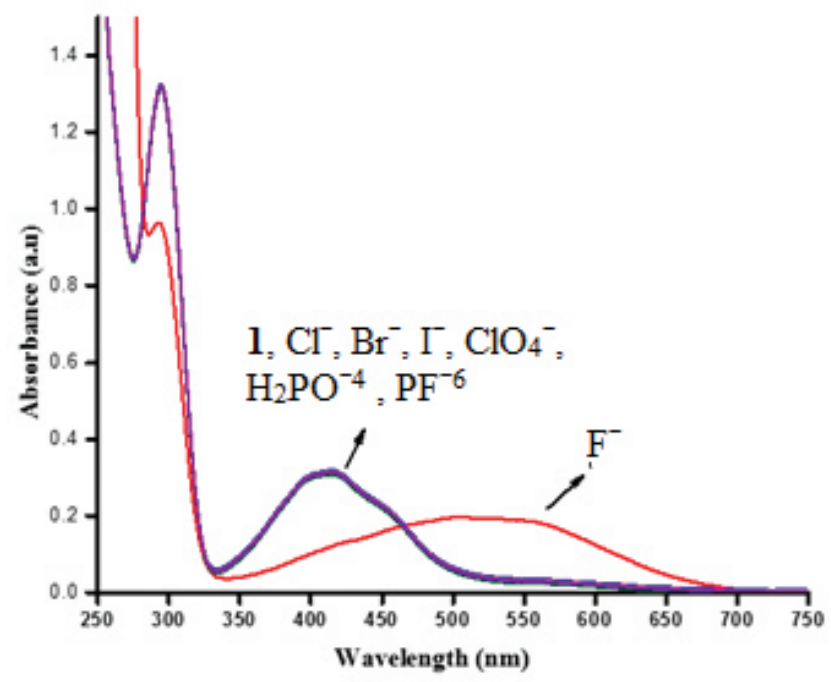

Figure 3 Absorption spectral changes of chemosensor $1(0.01 \mu \mathrm{M})$ upon addition of $1 \mu \mathrm{M}$ solutions of different anions.

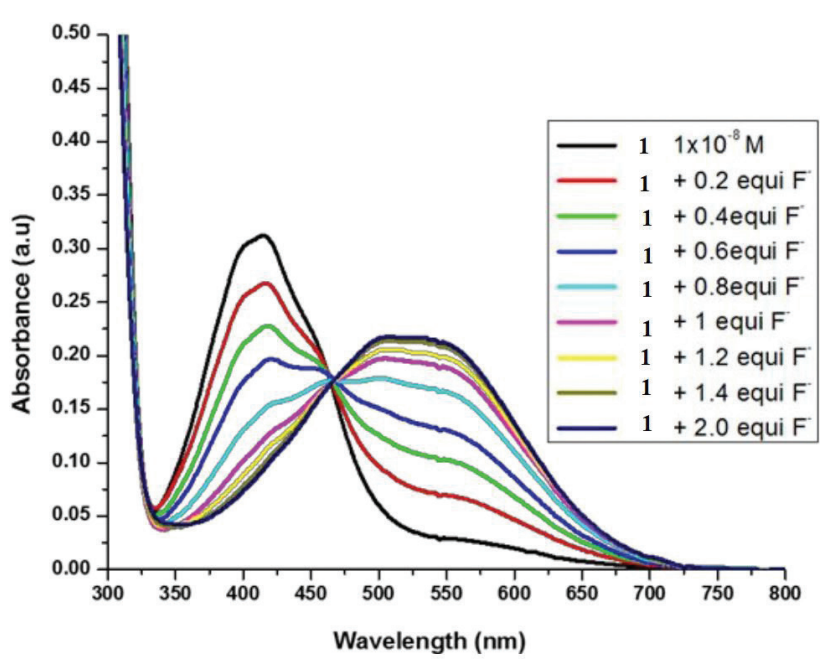

Figure 4 UV-Vis titrations of $1(0.01 \mu \mathrm{M})$ with different concentrations of TBAF in MeCN. deduced that the intermolecular interaction between 1 and the fluoride anion results in complete deprotonation rather than hydrogen bonding, owing to its greater influence on the electron density of the isatin nucleus.

The binding interactions of 1 with the analyte was further examined via Job's plot analysis. As shown in Figure 6, the gradual increase in the intensity of the absorption band of 1 with the increase in fluoride anion concentration showed a linear relationship up to one equivalent of fluoride anion, signifying a 1:1 binding ratio between 1 and the $\mathrm{F}^{-}$ion. Moreover, according to the UV-Vis titration experiment the chemosensor 1 showed a detection limit [61] of $0.367 \mathrm{ppm}$ with $\mathrm{R}^{2}=0.9654$.

\section{Computational studies}

The observed selectivity and sensitivity of chemosensor 1 towards the $\mathrm{F}^{-}$anion can be explained on the basis of density functional theory (DFT) calculations. The optimized structures of 1 and its anion in the ground state were obtained from DFT/B3LYP/6-31G using the Gaussian 09 software package. Figure 7 shows the optimized structures, graphical representations (isodensity surface plots) of the LUMO (lowest unoccupied molecular orbital) and HOMO (highest occupied molecular orbital) of 1 and its anion. Figures 7 also displays the band gaps and energy

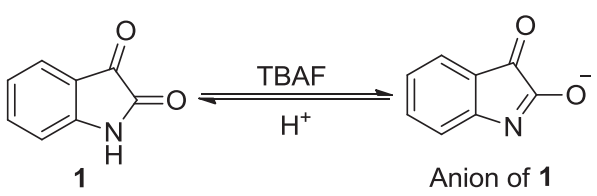

Figure 5 Proposed mechanism of detection of 1.

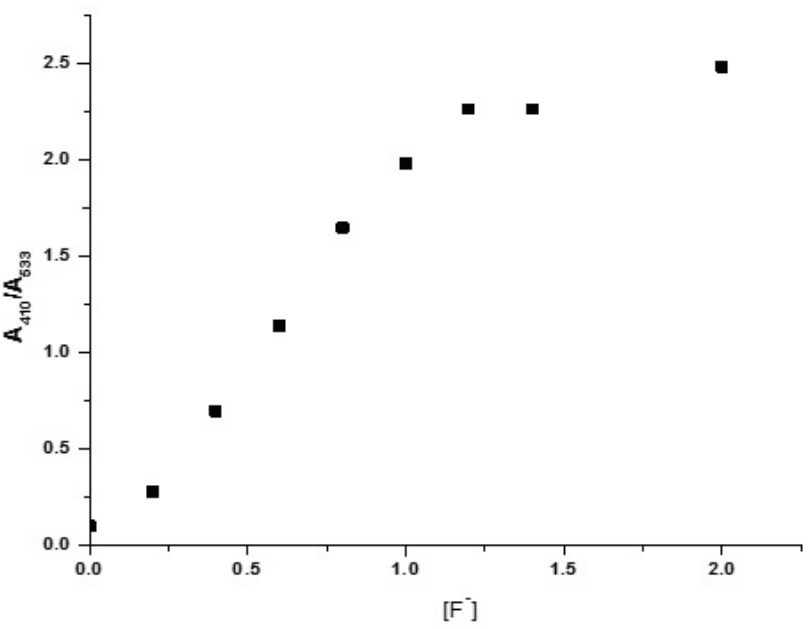

Figure 6 Linear regression graph between added concentration of $\operatorname{TBAF}\left(0-2 \times 10^{-8} \mathrm{M}\right)$ and of relative absorbance (at 410 and $533 \mathrm{~nm}$ ) of chemosensor 1 . 


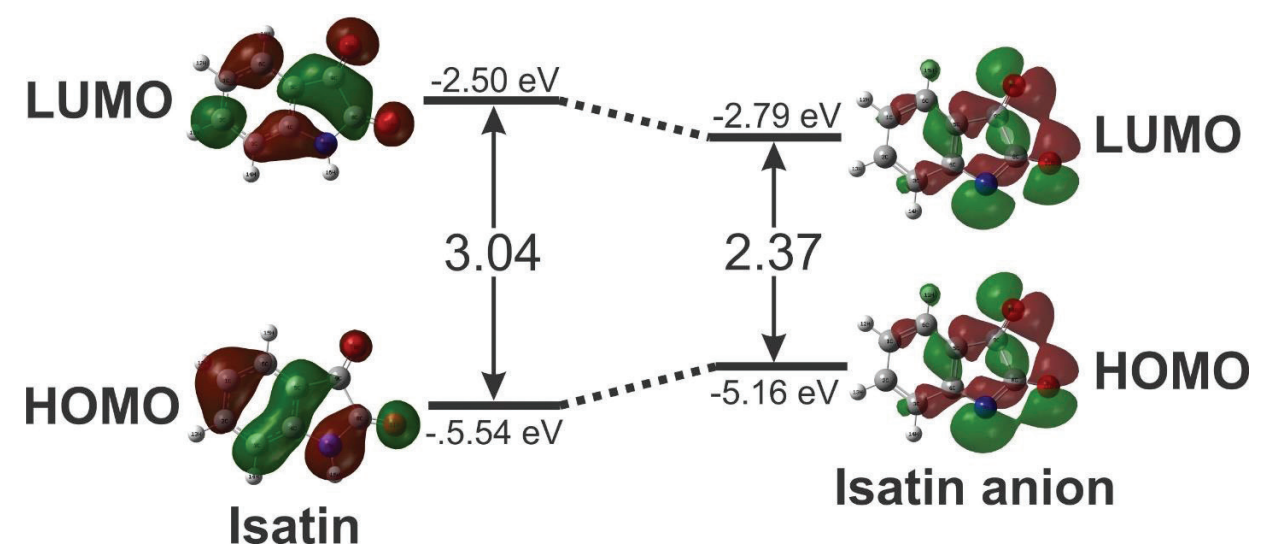

Figure 7 Frontier molecular orbitals of chemosensor 1 and its anion.

level values. The HOMO energy level $(-5.16 \mathrm{eV})$ of the isatin anion is higher than that of the chemosensor $1(-5.54 \mathrm{eV})$ and the LUMO energy level $(-2.79 \mathrm{eV})$ of the isatin anion is lower than that of the chemosensor $1(-2.50 \mathrm{eV})$; hence, the band gap between the LUMO and HOMO of the isatin anion $(2.37 \mathrm{eV})$ is smaller than that of the sensor $1(3.04 \mathrm{eV})$, which is in good agreement with the bathochromic shift in absorption $\left(\lambda_{\max }=533 \mathrm{~nm}\right)$ detected upon treatment of chemosensor 1 with $\mathrm{F}^{-}$anions. It is noted that the relation between the energy band gap and absorption spectra was estimated from the Planck-Einstein relation [62].

In the case of 1 , both the HOMO and LUMO were localized throughout the whole molecule. However, in the case of the anion of 1, spatial separation of FMOs is noticeable, i.e., both HOMO and LUMO were chiefly localized on the electron-richer pyrrolidine ring. This orbital distribution revealed that the deprotonation of 1 should impact the LUMO and HOMO evenly and therefore constitute the basis of an optical response of 1 to addition of $\mathrm{F}^{-}$ (Figure 7).

\section{Conclusions}

In summary, a commercially available colored organic compound, isatin, was investigated for selective fluoride anion sensing using UV/Vis spectroscopy and naked-eye experiments. The results reveals that isatin is a novel colorimetric chemosensor for selective detection of fluoride ions in acetonitrile. Isatin shows changes in both its color and its UV-Vis absorption spectra upon the addition of fluoride, while the other anions, such as $\mathrm{Cl}^{-}, \mathrm{Br}^{-}, \mathrm{I}^{-}, \mathrm{ClO}_{4}^{-}, \mathrm{H}_{2} \mathrm{PO}_{4}^{-}$and $\mathrm{PF}_{6}^{-}$, did not produce any noticeable change. The selectivity of the isatin receptor towards the fluoride anion over the other anions is attributed to the small size and greater charge density, hence Lewis basicity, of the fluoride anion, which led to the complete deprotonation of the receptors. However, the other anions/Lewis bases were not strong enough to deprotonate the receptors. The results further demonstrated that the isatin receptor respond in microseconds and in linear fashion over a wide range of fluoride concentrations and a very low concentration of fluoride anion could be detected, i.e., the limit of detection of isatin is $0.367 \mathrm{ppm}$. Owing to its solubility in water as well as in organic solvents, isatin can be useful in the detection of biologically or environmentally important fluoride anions in both aqueous and organic media. The high selectivity and sensitivity of isatin towards fluoride anions makes this molecule highly attractive and this study will provide an ideal platform to explore this molecule further in the field of anion sensing/recognition.

\section{Experimental}

\section{Naked-eye detection studies}

For naked eye experiments, $1(0.01 \mu \mathrm{M}) 3 \mathrm{ml}$ was placed into a glass vial and 1 equivalent of each anion was added to the glass vial.

\section{Recognition studies}

The UV-Vis spectra were recorded using a BioMate 3S UV-Visible Spectrophotometer (Thermo Scientific). All absorbance assays were performed in $100 \mu \mathrm{L}$ quartz cuvettes. The recognition studies were performed at $25^{\circ} \mathrm{C}$. $2 \mu \mathrm{M}$ solutions of $1 \mathrm{in}$ acetonitrile were prepared and $2.5 \mathrm{~mL}$ of each was taken in volumetric flasks. The binding behavior of 1 was studied by adding $2.5 \mathrm{~mL}$ solutions ( $4 \mu \mathrm{M})$ 
of different anions (TBAF, TBACl, TBABr, TBAI, TBAPF ${ }_{6}$, $\mathrm{TBAH}_{2} \mathrm{PO}_{4}$ and $\mathrm{TBAClO}_{4}$ ) into the solutions of 1 and the absorption spectrum of each solution was recorded.

\section{Titration studies}

For titration studies, 0.2, 0.4, 0.6, 0.8, 1.0, 1.2, 1.4 and 2.0 equivalents of $\mathrm{F}^{-}$were individually added to volumetric flasks containing 1 and absorption spectra were recorded for set after each aliquot addition of $\mathrm{F}^{-}$.

\section{Selectivity studies}

Possible interference due to different anions was studied by adding one equivalent of different anions to $1 \mu \mathrm{M}$ solution of 1 . Absorption spectra were recorded and no interference was found.

\section{Sensitivity studies}

The sensitivity of 1 towards fluoride anion was checked by adding a solution of $\mathrm{F}^{-}(\mu \mathrm{M})$ to a solution of $1(0.01 \mu \mathrm{M})$ and absorption spectra were recorded as a function of time at short intervals.

Acknowledgments: We are grateful to The World Academy of Sciences (TWAS) for financial support (Project No. 13-419 RG/PHA/AS_CUNESCO FR: 3240279216) and Quaid-i-Azam University for financial support under the URF program.

\section{References}

[1] Molina P, Zapata F. Caballero, A. Anion Recognition Strategies Based on Combined Noncovalent Interactions. Chem Rev. 2017;117:9907-72.

[2] Zhao Y, Cotelle Y, Liu L, López-Andarias J, Bornhof AB, Akamatsu $M$, et al. The Emergence of Anion- $\pi$ Catalysis. Acc Chem Res. 2018;51:2255-63.

[3] He Q, Vargas-Zúñiga GI, Seung Kim H, Kim SK, Sessler JL. Macrocycles as Ion Pair Receptors. Chem Rev. 2019;119:9753-835.

[4] Gale PA, Howe EN, Wu X. Anion Receptor Chemistry. Chem. 2016;1:351-422.

[5] Langton MJ, Serpell CJ, Beer PD. Anion Recognition in Water: Recent Advances from a Supramolecular and Macromolecular Perspective. Angew Chem Int Ed. 2016;55:1974-87.

[6] Naseer MM, Jurkschat K. Organotin-based receptors for anions and ion pairs. Chem Commun (Camb). 2017;53:8122-35.

[7] Busschaert N, Caltagirone C, Van Rossom W, Gale PA. Applications of Supramolecular Anion Recognition. Chem Rev. 2015;115:8038-155.
[8] Gale PA, Caltagirone C. Anion sensing by small molecules and molecular ensembles. Chem Soc Rev. 2015;44:4212-27.

[9] Giese M, Albrecht M, Rissanen K. Anion-pi Interactions with Fluoroarenes. Chem Rev. 2015;115:8867-95.

[10] Gale PA, Perez-Tomas R, Quesada R. Anion Transporters and Biological Systems. Acc Chem Res. 2013;46:2801-13.

[11] Valkenier H, Davis AP. Making a Match for Valinomycin: Steroidal Scaffolds in the Design of Electroneutral, Electrogenic Anion Carriers. Acc Chem Res. 2013;46:2898-909.

[12] Gale PA. From Anion Receptors to Transporters. Acc Chem Res. 2011;44:216-26.

[13] Custelcean R. Anions in crystal engineering. Chem Soc Rev. 2010;39:3675-85.

[14] Carroll CN, Naleway JJ, Haley MM, Johnson DW. Arylethynyl receptors for neutral molecules and anions: emerging applications in cellular imaging. Chem Soc Rev. 2010;39:3875-88.

[15] Bianchi A, Bowman-James K, García-España E. Supramolecular Chemistry of Anions. New York: Wiley-VCH; 1997.

[16] Sessler JL, Gale PA, Cho W (Stoddart JF, editor). S Anion Receptor Chemistry. Cambridge, U.K.: Royal Society of Chemistry; 2006.

[17] Alberts B, Bray D, Lewis J, Raff M, Roberts K, Watson JD. Molecular Biology of the Cell. 3rd ed. New York: Garland Science; 1994.

[18] Kornak U, Kasper D, Bosl MR, Kaiser E, Schweizer M, Schulz A, et al. Loss of the CIC-7 Chloride Channel Leads to Osteopetrosis in Mice and Man. Cell. 2001;104:205-15.

[19] Scott DA, Wang R, Kreman TM, Sheffield VC, Karniski LP. The Pendred syndrome gene encodes a chloride-iodide transport protein. Nat Genet. 1999;21:440-3.

[20] Devuyst O, Christie PT, Courtoy PJ, Beauwens R, Thakker RV. Intra-renal and subcellular distribution of the human chloride channel, CLC-5, reveals a pathophysiological basis for Dent's disease. Hum Mol Genet. 1999;8:247-57.

[21] Simon DB, Bindra RS, Mansfield TA, Nelson-Williams C, Mendonca E, Stone RP, et al. Mutations in the chloride channel gene, CLCNKB, cause Bartter's syndrome type III. Nat Genet. 1997;17:171-8.

[22] Anderson MP, Gregory RJ, Thompson S, Souza DW, Paul S, Mulligan RC, et al. J Demonstration that CFTR is a chloride channel by alteration of its anion selectivity. Science. 1991;253:202-5.

[23] Sessler JL, Davis JM. Sapphyrins: Versatile Anion Binding Agents. Acc Chem Res. 2001;34:989-97.

[24] Thale PB, Borase PN, Shankarling GS. "turn on" fluorescent and chromogenic chemosensor for fluoride anion: experimental and DFT studies. Inorg Chem Front. 2016;3:977-84.

[25] Heras JD, Aldámiz-Echevarría L, Martínez-Chantar ML, Delgado TC. An update on the use of benzoate, phenylacetate and phenylbutyrate ammonia scavengers for interrogating and modifying liver nitrogen metabolism and its implications in urea cycle disorders and liver disease. Expert Opin Drug Metab Toxicol. 2017;13:439-48.

[26] Elser JJ, Bracken ME, Cleland EE, Gruner DS, Hillebrand H, Ngai JT, et al. Global analysis of nitrogen and phosphorus limitation of primary producers in freshwater, marine and terrestrial ecosystems. Ecol Lett. 2007;10:1135-42.

[27] Bose P, Ravikumar I, Ghosh P. Anion binding in the C $3 \mathrm{v}$-symmetric cavity of a protonated tripodal amine receptor: 
potentiometric and single crystal X-ray studies. Inorg Chem. 2011;50:10693-702.

[28] Wade CR, Broomsgrove AE, Aldridge S, Gabbaï FP. Fluoride Ion Complexation and Sensing Using Organoboron Compounds. Chem Rev. 2010;110:3958-84.

[29] Zhou Y, Zhang JF, Yoon J. Fluorescence and Colorimetric Chemosensors for Fluoride-Ion Detection. Chem Rev. 2014;114(10):5511-71.

[30] Jagtap S, Yenkie MK, Labhsetwar N, Rayalu S. Fluoride in Drinking Water and Defluoridation of Water. Chem Rev. 2012;112:2454-66.

[31] Wu X, Wang H, Yang S, Tian H, Liu Y, Sun B. Highly Sensitive Ratiometric Fluorescent Paper Sensors for the Detection of Fluoride Ions. ACS Omega. 2019;4:4918-26.

[32] Zhou X, Lai R, Li H, Stains Cl. The 8-silyloxyquinoline scaffold as a versatile platform for the sensitive detection of aqueous fluoride. Anal Chem. 2015;87:4081-6.

[33] Campus G, Cagetti MG, Spano N, Denurra S, Cocco F, Bossù $M$, et al. Laboratory enamel fluoride uptake from fluoride products. Am J Dent. 2012;25:13-6.

[34] Aoun A, Darwiche F, Al Hayek S, Doumit J. The Fluoride Debate: The Pros and Cons of Fluoridation. Prev Nutr Food Sci. 2018;23:171-80.

[35] Pitt P, Berry H. Fluoride treatment in osteoporosis. Postgrad Med J. 1991;67:323-6.

[36] Demos L, Kazda H, Cicuttini FM, Sinclair MI, Fairley CK. Water fluoridation, osteoporosis, fractures-recent developments. Aust Dent J. 2001;46:80-7.

[37] Lennon MA. One in a million: the first community trial of water fluoridation. Bull World Health Organ. 2006;84:759-60.

[38] Rwenyonyi CM, Bjorvatn K, Birkeland JM, Haugejordan 0. Altitude as a risk indicator of dental fluorosis in children residing in areas with 0.5 and $2.5 \mathrm{mg}$ fluoride per litre in drinking water. Caries Res. 1999;3:3267-74.

[39] Ba Y, Zhu JY, Yang YJ, Yu B, Huang H, Wang G, et al. Serum calciotropic hormone levels, and dental fluorisis in children exposed to different concentrations of fluoride and iodine in drinking water. Chin Med J (Engl). 2010;123:675-9.

[40] Shashi A, Singh JP, Thapar SP. Toxic effects of fluoride on rabbit kidney. Fluoride. 2002;35:38-50.

[41] Czarnowski W, Krechniak J, Urbańska B, Stolarska K, Taraszewska-Czarnowska M, Muraszko-Klaudel A. The impact of water-borne fluoride on bone density. Fluoride. 1999;32:91-5.

[42] Assadollahnejad N, Kargar M, Darabi HR, Abouali N, Jamshidi $\mathrm{S}$, Sharifi A, et al. A new ratiometric, colorimetric and "turn-on" fluorescent chemosensor for the detection of cyanide ions based on a phenol-bisthiazolopyridine hybrid. New J Chem. 2019;43:13001-9.

[43] Li Z, Dai Y, Lu Z, Pei Y, Song Y, Zhang L, et al. A Photoswitchable Triple Chemosensor for Cyanide Anion Based on Dicyanovinyl-Functionalized Dithienylethene. Eur J Org Chem. 2019;22:3614-21.

[44] Goswami S, Chakrabarty R. Highly Selective Colorimetric Fluorescent Sensor for Pb2+. Eur J Org Chem. 2010;20:3791-5.

[45] Cho EJ, Ryu BJ, Lee YJ, Nam KC. Visible Colorimetric Fluoride Ion Sensors. Org Lett. 2005;7:2607-9.

[46] Chen J, Shu W, Wang, E. A fluorescent and colorimetric probe based on isatin-appended rhodamine for the detection of Hg2+. Chem Res Chin Univ. 2016;32:742-5.
[47] Vine KL, Matesic L, Locke JM, Scropeta D. Recent highlights in the development of isatin-based anticancer agents. Adv. Anticancer Agents Med. Chem. 2013;2:254-312.

[48] Pandeya SN, Smitha S, Jyoti M, Sridhar SK. Biological activities of isatin and its derivatives. Acta Pharm. 2005;55:27-46.

[49] Medvedev A, Igosheva N, Crumeyrolle-Arias M, Glover V. Isatin: role in stress and anxiety. Stress. 2005;8:175-83.

[50] Medvedev A, Buneeva O, Glover V. Biological targets for isatin and its analogues: implications for therapy. Biol. Targets Ther. 2007;1:151-62.

[51] Shakir M, Abbasi A. Solvent dependant isatin-based Schiff base sensor as fluorescent switch for detection of Cu2+ and S2- in human blood serum. Inorg Chim Acta. 2017; 465:14-25.

[52] Dhara A, Guchhait N, Kar SK. A novel Cr3+ fluorescence turn-on probe based on rhodamine and isatin framework. J Fluoresc. 2015;25:1921-9.

[53] Horváth M, Cigáň M, Filo J, Jakusová K, Gáplovský M, Šándrik R. Gáplovský A. Isatin pentafluorophenylhydrazones: interesting conformational change during anion sensing. RSC Advances. 2016;6:109742-50.

[54] Liu K, Zhao X, Huo J, Neufeld K, Dong M, Zhu X. Anioninduced optical outputs of an isatin-based colorimetric $\mathrm{HNI}$ sensor for construction of sequential molecular logic gates and a set-reset memorized device. Sens Actuators B Chem. 2016;226:465-70.

[55] Hussain M, Bauzá A, Frontera A, Lo KM, Naseer MM. Structure guided or structure guiding? Mixed carbon/hydrogen bonding in bis-Schiff base of $\mathrm{N}$-allyl isatin. CrystEngComm. 2018;20:150-4.

[56] Pervez H, Khan N, Iqbal J, Zaib S, Yaqub M, Naseer MM. Synthesis and in vitro bio-activity evaluation of N4-benzyl substituted 5-chloroisatin 3-thiosemicarbazones as urease and glycation inhibitors. Acta Chim Slov. 2018;65:108-18.

[57] Pervez H, Khan N, Iqbal J, Zaib S, Yaqub M, Tahir MN, et al. Synthesis, crystal structure, molecular docking studies and bio-evaluation of some N4-benzyl substituted isatin3-thiosemicarbazones as antiurease and antiglycating agents. Heterocycl Commun. 2018;24:51-8.

[58] Pervez H, Ahmad M, Hadda TB, Toupet L, Naseer MM. Synthesis and fluorine-mediated interactions in methanol-encapsulated solid state self-assembly of an isatin-thiazoline hybrid. J Mol Struct. 2015;1098:124-9.

[59] Ahmad M, Pervez H, Ben Hadda T, Toupet L, Naseer MM. Synthesis and solid state self-assembly of an isatin-thiazoline hybrid driven by three self-complementary dimeric motifs. Tetrahedron Lett. 2014;55:5400-3.

[60] Ahmed M, Hameed S, Ihsan A, Naseer MM. Fluorescent thiazolsubstituted pyrazoline nanoparticles for sensitive and highly selective sensing of explosive 2,4,6-trinitrophenol in aqueous medium. Sens Actuators B Chem. 2017;248:57-62.

[61] The limit of detection (LOD) was calculated from the linear regression graph shown in Figure 3.5 according to the IUPAC definition. The equation is given below: $L O D=3.3 \sigma / \mathrm{k}$ Where $\mathrm{K}$ is the slope of the graph and $\sigma$ is the standard deviation of the $y$-intercept of the regression line.

[62] Dharma J, Pisal A, Shelton CT. Simple method of measuring the band gap energy value of $\mathrm{TiO} 2$ in the powder form using a UV/Vis/NIR spectrometer. Application Note Shelton (CT): PerkinElmer; 2017. 